\title{
Predictive factors for early hypothyroidism following the radioactive iodine therapy in Graves' disease patients
}

\author{
Rui-Ting $\mathrm{Hu}^{1,2}$, De-Shan $\mathrm{Liu}^{1}$ and Bin $\mathrm{Li}^{3^{*}}$ (D)
}

\begin{abstract}
Background: Radioactive iodine (RAl) therapy is an important treatment option for Graves' disease (GD), the main side effect of RAl treatment is hypothyroidism, and the factors resulting in hypothyroidism are still controversial. The purpose of this retrospective study was to clarify the possible risk factors of early hypothyroidism after RAl therapy in Graves' disease.

Methods: We reviewed 312 GD patients treated with RAl between January 2017 to December 2018, collected the potential risk factors, and analyzed the relationship between these variables and early hypothyroidism.

Results: After 6 months' follow-up, 218 (69.87\%) patients were evaluated as early hypothyroid. Male gender, shorter duration of disease, smaller thyroid weight, lower 2-h radioactive iodine uptake (RAIU), 6-h RAIU, 24-h RAIU and 6/ 24-h uptake ratio, lower administered dosages were significantly associated with early hypothyroidism. Logistics regression analysis showed that male gender, smaller thyroid weight and lower 6-h RAIU were associated with early hypothyroidism. Multi-factors combined ROC curve analysis suggested that the predictive power of male gender, smaller thyroid weight and lower 6-h RAIU for early hypothyroidism was 0.711 .

Conclusions: Our results show that RAI is an effective therapy for GD and most of the cured patients became to hypothyroid within 6 months. Male gender, smaller thyroid weight and lower 6-h RAIU are the main risk factors for early hypothyroidism.
\end{abstract}

Keywords: Graves' disease, Radioactive iodine, Therapy, Early hypothyroidism

\section{Background}

Hyperthyroidism is a clinical syndrome caused by increased thyroid hormone in blood, it can lead to multiple complications, including cardiac, hepatic and hematologic system complications. More than $80 \%$ of the hyperthyroidism are caused by Graves' disease (GD), and $3 \%$ of women and $0.5 \%$ of men may suffer GD in their lifetime [1]. The incidence is 20 to 30 cases per year per 100,000 persons [2]. The incidence peaks

\footnotetext{
* Correspondence: leedonggonk@sina.com

${ }^{3}$ Department of Nuclear Medicine, Linyi People's Hospital, Cheeloo College of Medicine, Shandong University, Linyi 276000, Shandong, China

Full list of author information is available at the end of the article
}

between 30 and 60 years of age, but people can be affected at any age $[1,2]$. Common symptoms are palpitations, fatigue, tremor, anxiety, disturbed sleep, weight loss, heat intolerance, sweating, and polydipsia [3].

GD can be treated by anti-thyroid drugs (ATD), radioactive iodine (RAI) or thyroidectomy [4, 5]. ATD have lower risk of permanent hypothyroidism compared to RAI or thyroidectomy, but they are likely to cause frequently mild side effects and some rare but severe side effects, such as rash, vasculitis, agranulocytosis and acute hepatonecrosis, so the patients taking medications requires frequent hematological examinations [6]. Commonly, after 12-18 months' drug treatment, the risk of

(c) The Author(s). 2020 Open Access This article is licensed under a Creative Commons Attribution 4.0 International License, which permits use, sharing, adaptation, distribution and reproduction in any medium or format, as long as you give appropriate credit to the original author(s) and the source, provide a link to the Creative Commons licence, and indicate if changes were made. The images or other third party material in this article are included in the article's Creative Commons licence, unless indicated otherwise in a credit line to the material. If material is not included in the article's Creative Commons licence and your intended use is not permitted by statutory regulation or exceeds the permitted use, you will need to obtain permission directly from the copyright holder. To view a copy of this licence, visit http://creativecommons.org/licenses/by/4.0/ The Creative Commons Public Domain Dedication waiver (http://creativecommons.org/publicdomain/zero/1.0/) applies to the data made available in this article, unless otherwise stated in a credit line to the data. 
recurrence is around $50 \%[7,8]$. Compared to ATD, RAI is a definitive treatment of hyperthyroidism and can improve hyperthyroidism quickly $[9,10]$. Due to its low cost and high efficiency, lots of patients are tend to use RAI therapy to cure GD all over the world $[11,12]$.

Although the side effects of RAI are rare, mild and transient, it could result in hypothyroidism frequently. The aim of this study is to examine the occur of early hypothyroidism in GD patients treated with RAI in our center between January 2017 to December 2018, and to identify the significant risk factors influencing the occurrence of early hypothyroidism.

\section{Methods}

\section{Patients}

As shown in Fig.1, in this retrospective study, 537 GD patients treated with RAI between January 2017 to December 2018 at Linyi People's Hospital Affiliated to Shandong University (Linyi, China) were collected and reviewed. The inclusion criteria including: (1) Diffuse enlargement of the thyroid gland, symptoms of high metabolism including excitable, palpitation, hands tremble or emaciation; (2) suppressed serum thyrotropin (TSH) $(<0.55 \mu \mathrm{U} / \mathrm{mL})$, elevated serum free triiodothyronine (FT3) $(>6.5 \mathrm{pmol} / \mathrm{L})$, free thyroxine (FT4) $(>22.7 \mathrm{pmol} /$ L) and TSH receptor antibody (TRAb). The exclusion criteria including: (1) Patients with other causes of hyperthyroidism, such as toxic multinodular goiter and single toxic adenoma; (2) Patients can't complete the follow-up within 6 months; (3) Patients with history of thyroidectomy; (4) Patients with history of RAI treatment. After the evaluation, 225 patients didn't meet the entry criteria, so the final number of the patients included in this study was 312 . The following risk factors were collected and analyzed, including gender, age, duration of disease, weight of thyroid, ATD therapy history, FT3, FT4, TSH, TRAb, thyroperoxidase antibody (TPOAb), 2-h RAIU, 6-h RAIU, 24-h RAIU, 6/24-h uptake ratio and the administered dosages according to the calculated dosage method. The study was approved by the ethics committee of Linyi People's Hospital Affiliated to Shandong University and was performed in accordance with the guidelines and regulations. Informed written consent was obtained from the all patients.

\section{Radioactive iodine uptake measurements}

Before the test, all the patients need to stop taking iodine-rich foods, iodine-containing drugs and ATD for 2 weeks. During the examination, the patient took 131I solution $370 \mathrm{kBq}(10 \mu \mathrm{Ci})$ in the morning without eating any food, and kept fasting for an extra hour after taking it. Then the thyroid radioactivity counts at 2,6 , and $24 \mathrm{~h}$ after oral administration of the 131I solution were measured [13]. RAIU was calculated according to the following formula:

$$
\text { RAIU }(\%)=\frac{\text { the activity over the thyroidregion-background }}{\text { the activity measured from a standard containing-background }} \times 100 \%
$$

\section{Thyroid volume and weight estimation}

The thyroid volume is measured by thyroid ultrasonography. In short, the patient lies on the back in the examination bed, fully exposing the neck, then the size of thyroid was measured independently by the two same experienced ultrasonic technicians using Ultrasound System (GE Vingmed Ultrasound AS, Horten, Norway).

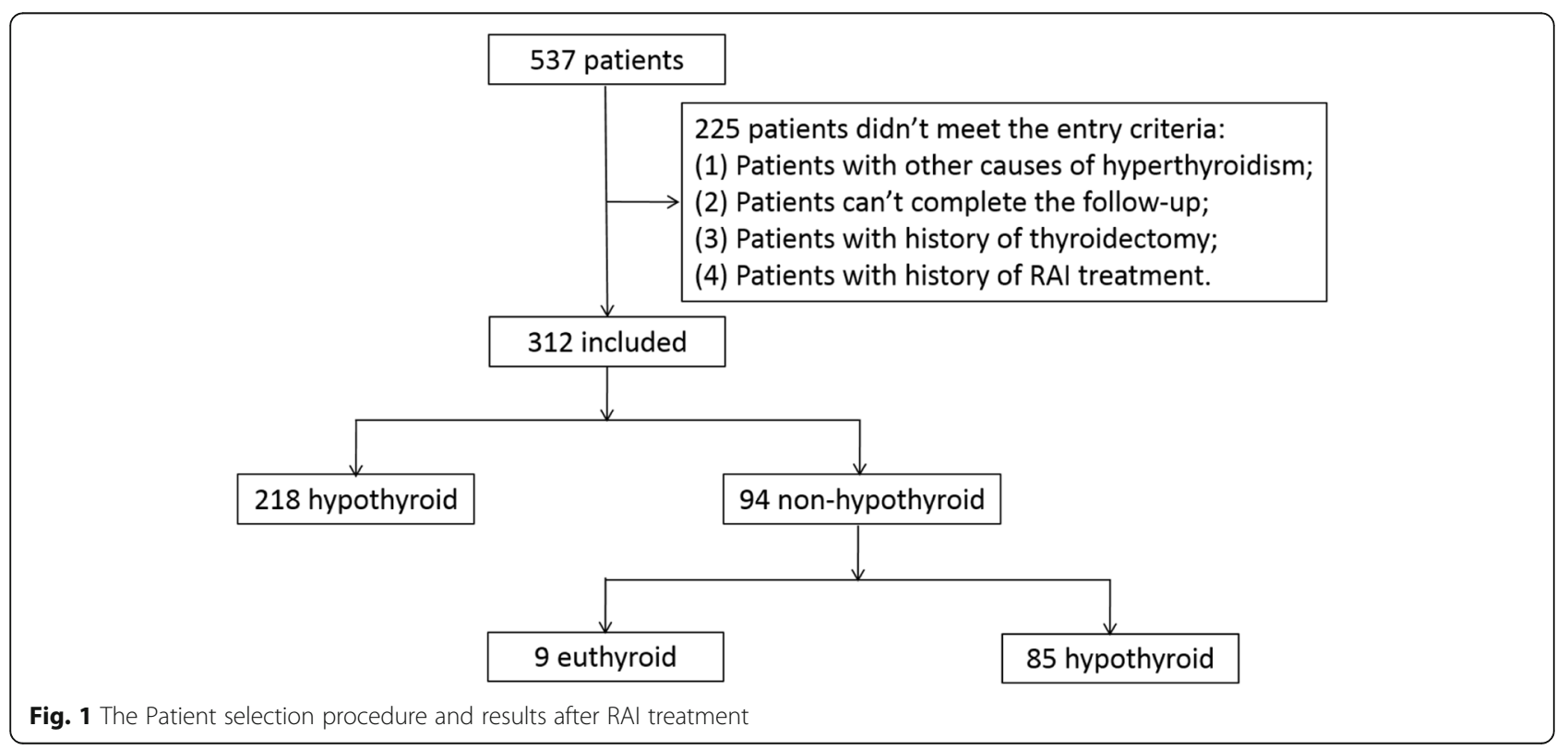


Table 1 The basic clinical characteristics of patients in this study

\begin{tabular}{ll}
\hline Variables & Range \\
\hline Male: Female & $54(17.3 \%): 258(82.7 \%)$ \\
Age (years) & $45.07 \pm 12.79$ \\
Duration of Graves' hyperthyroidism (months) & $6(1,376)$ \\
Thyroid weight (g) & $52.21(19.12,239.00)$ \\
ATD therapy history (Male: Female) & $42(77.8 \%): 205(80.7 \%)$ \\
Propyltiouracil (Male: Female) & $5(11.9 \%): 26(12.7 \%)$ \\
Methimazole (Male: Female) & $37(88.1 \%): 179(87.3 \%)$ \\
FT3 (pmol/L) & $22.08(4.35,36.70)$ \\
FT4 (pmol/L) & $51.68(3.51,154.80)$ \\
TSH (uIU/mL) & $0.005(0.001,0.250)$ \\
TPOAb (IU/mL) & $1300(23.30,1300.00)$ \\
TRAb (IU/mL) & $12.72(0.30,40.00)$ \\
2-h RAIU & $37.25(7.80,83.69)$ \\
6-h RAIU & $66.24(14.40,95.62)$ \\
24-h RAIU & $72.52(27.29,99.90)$ \\
6/24-h uptake ratio & $92.07(49.48,126.70)$ \\
Dose of RAl (mCi) & $8.81 \pm 2.90$
\end{tabular}

FT3 Free triiodothyronine; FT4 Free thyroxine; TSH Thyrotropin; TPOAb Thyroperoxidase antibody; TRAb Thyrotropin receptor antibody; RAIU Radioactive iodine uptake

The thyroid weight was calculated with the following formula [14]:

Thyroidweight $(\mathrm{g})=0.479 \times[$ lenght $(\mathrm{cm}) \times$ width $(\mathrm{cm}) \times$ thickness $(\mathrm{cm})$ of left lobe + length $(\mathrm{cm}) \times$ width $(\mathrm{cm}) \times$ thickness $(\mathrm{cm})$ of right lobe]

\section{Radioactive iodine dose calculation}

The dose of RAI was calculated based on thyroid weight and RAIU as previously described [15]. In short, it was calculated according to the following formula:

$$
\text { Oral RAI dose }(\mathrm{mCi})=\frac{\text { thyroidweight }(\text { gram }) \times 0.1(\mathrm{mCi} / \mathrm{gram})}{24 \mathrm{~h} \operatorname{RAIU}(\%)}
$$

\section{Radioactive iodine therapy}

All the patient need to stop ATD and iodine-containing drugs for 2 weeks prior to RAI treatment, and followed a low-iodine diet for 2 weeks. After fasting and water deprivation for $8 \mathrm{~h}$, all the patients took RAI orally in the morning. After taking RAI, the patients need to continue fasting and water deprivation for extra $2 \mathrm{~h}$ to avoid the effects of food on iodine absorption.

\section{Follow-up}

Evaluation of the response was based on clinical manifestation and laboratory results, which was performed at each visiting per month after the treatments. The outcomes of RAI were classified as follows: (a) persistent hyperthyroidism-increased hormone levels (FT3 $>6.5$ $\mathrm{pmol} / \mathrm{L}, \quad \mathrm{FT} 4>22.7 \mathrm{pmol} / \mathrm{L}, \quad \mathrm{TSH}<0.55 \mu \mathrm{U} / \mathrm{mL}$ ) and symptoms of hyperthyroidism after 6 months' follow-up; (b) euthyroidism-normal hormone levels (FT3 3.5 to $6.5 \mathrm{pmol} / \mathrm{L}$, FT4 11.5 to $22.7 \mathrm{pmol} / \mathrm{L}$, TSH 0.55 to 4.78 $\mu \mathrm{U} / \mathrm{mL}$ ), and no symptoms of hyperthyroidism after 6 months' follow-up; and (c) hypothyroidism-decreased hormone levels $(\mathrm{FT} 3<3.5 \mathrm{pmol} / \mathrm{L}, \quad \mathrm{FT} 4<11.5 \mathrm{pmol} / \mathrm{L}$,

Table 2 The comparation of early hypothyroid risk factors between non-hypothyroid group and hypothyroid group

\begin{tabular}{llll}
\hline Variables & Non-hypothyroid & Hypothyroid & $P$ value \\
\hline Male: Female & $4: 90$ & $50: 168$ & $45.60 \pm 12.63$ \\
Age (years) & $43.82 \pm 13.17$ & $6(1,376)$ & 0.001 \\
Duration of Graves' hyperthyroidism (months) & $12(1,240)$ & $184: 45$ & 0.261 \\
ATD therapy history: Non-ATD therapy history & $63: 20$ & $49.82(19.12,163.3)$ & 0.019 \\
Thyroid weight (g) & $60.83(23.02,239.00)$ & $21.33(4.35,36.69)$ & 0.001 \\
FT3 (pmol/L) & $22.48(4.68,36.70)$ & $49.55(13.04,154.80)$ & 0.341 \\
FT4 (pmol/L) & $57.75(3.51,154.80)$ & $0.005(0.001,0.250)$ & 0.091 \\
TSH (ulU/mL) & $0.005(0.001,0.100)$ & $1300(27.00,1300.00)$ & 0.304 \\
TPOAb (IU/mL) & $1300(23.30,1300.00)$ & $12.72(0.30,40.00)$ & 0.514 \\
TRAb (IU/mL) & $13.56(0.30,40.00)$ & $35.49(9.01,81.98)$ & 0.601 \\
2-h RAIU & $39.86(7.80,83.69)$ & $65.41(16.53,95.51)$ & 0.009 \\
6-h RAIU & $70.38(14.40,95.62)$ & $71.37(27.29,97.11)$ & 0.001 \\
24-h RAIU & $74.20(29.10,99.90)$ & $90.94(51.77,126.70)$ & 0.008 \\
6/24-h uptake ratio & $94.59(49.48,115.87)$ & $8.52 \pm 2.78$ & 0.015 \\
Dose of RAI (mCi) & $9.48 \pm 3.08$ & 0.007 \\
\hline
\end{tabular}

FT3 Free triiodothyronine; FT4 Free thyroxine; TSH Thyrotropin; TPOAb Thyroperoxidase antibody; TRAb Thyrotropin receptor antibody; RAIU Radioactive iodine uptake 
Table 3 Logistic analysis of the risk factors of early hypothyroid

\begin{tabular}{|c|c|c|c|c|c|c|c|}
\hline \multirow[b]{2}{*}{ Variables } & \multirow[b]{2}{*}{ B } & \multirow[b]{2}{*}{ S.E. } & \multirow[b]{2}{*}{ Wald } & \multirow[b]{2}{*}{$P$} & \multirow[b]{2}{*}{$\mathrm{OR}$} & \multicolumn{2}{|l|}{$95 \% \mathrm{Cl}$} \\
\hline & & & & & & Lower & Upper \\
\hline Gender & 2.087 & 0.569 & 13.457 & 0.001 & 8.061 & 2.643 & 24.582 \\
\hline $6 \mathrm{~h}$ thyroid iodine uptake rate (\%) & 0.019 & 0.009 & 4.590 & 0.032 & 1.019 & 1.002 & 1.037 \\
\hline Thyroid weight (g) & 0.020 & 0.006 & 12.931 & 0.001 & 1.020 & 1.009 & 1.031 \\
\hline Constant & -7.236 & 1.329 & 29.653 & 0.001 & 0.001 & - & - \\
\hline
\end{tabular}

OR Odds ratio; $\mathrm{Cl}$ Confidence interval

$\mathrm{TSH}>4.78 \mu \mathrm{U} / \mathrm{mL}$ ) and symptoms of hypothyroidism within 6 months' follow-up.

\section{Statistical analysis}

The continuous variables were presented as mean \pm standard deviation and non-continuous variables were presented as median ( $\min , \max$ ). For normally distributed variables, the differences between the two groups were analyzed by the unpaired t-test. For non-normally distributed variables, the differences between the two groups were analyzed by the Mann-Whitney $U$ test. Categorical variables were reported in term of frequency and percentage. Categorical outcomes were analyzed by chi-square or Fisher exact test, as appropriate. Logistic regression analysis was used to evaluate the impact of particular parameters contributed to the outcome of hypothyroidism after the RAI treatment. The threshold for statistical significance was set to $p<0.05$. All statistical analyses were performed using SPSS software (Version 22.0; SPSS Inc., Chicago, IL, USA).

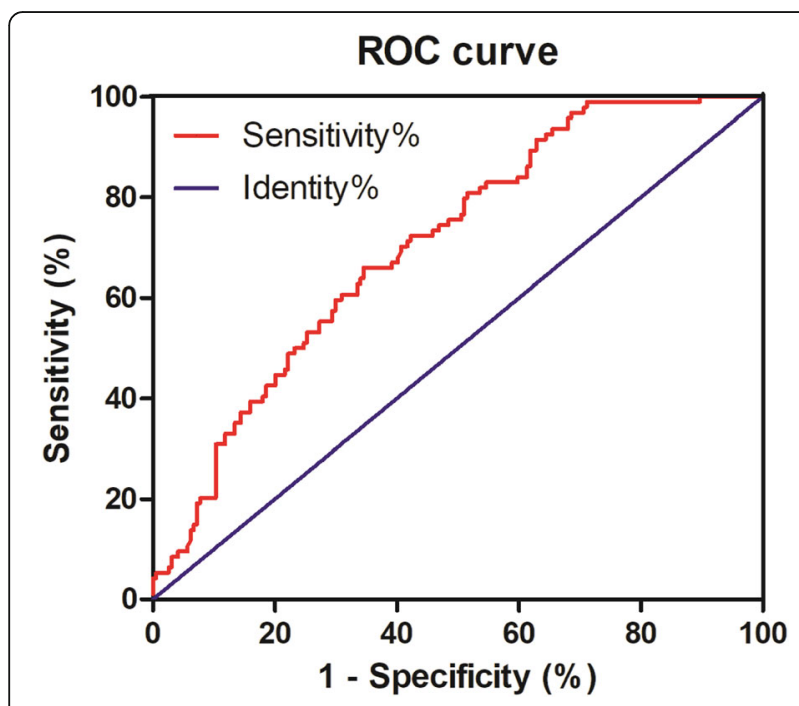

Fig. 2 The male gender, smaller thyroid weight and lower 6-h RAIU three-factors combined ROC curve analysis for early hypothyroidism

\section{Results}

The basic clinical characteristics of the patients in this study

As shown in Table 1, out of the 312 patients, 258 $(82.7 \%)$ were female and the remaining 54 (17.3\%) were male. The female to male ratio was $4.78: 1$, showing a higher incidence of Graves' hyperthyroidism in female than male subjects. The age range of the patients in our study was $18-75$ years, and the average age was 45.07 years. The median duration of the disease was 6 months, and the median weight of the thyroid was $52.21 \mathrm{~g}$. Before switched to the RAI therapy, 42 male patients and 205 female patients were initially treated with ATD. Five male patients and 26 female patients took propylthiouracil and the rest patients took methimazole. The median levels of FT3, FT4 and TSH were $22.08 \mathrm{pmol} / \mathrm{L}, 51.68$ $\mathrm{pmol} / \mathrm{L}$ and $0.005 \mathrm{uIU} / \mathrm{mL}$, respectively. The median levels of TPOAb and TRAb were $1300 \mathrm{IU} / \mathrm{mL}$ and 12.72 $\mathrm{IU} / \mathrm{mL}$. The median thyroid iodine uptake rates at 2,6 and $24 \mathrm{~h}$ were $37.25,66.24$ and $72.52 \%$, respectively. The $6 \mathrm{~h} / 24 \mathrm{~h}$ thyroid iodine uptake rates was $92.07 \%$. The average dose of RAI therapy was $8.81 \mathrm{mCi}$. Overall, as shown in Fig. 1, the total cure rate of RAI therapy of GD (including euthyroid patients and early hypothyroid patients) was $72.76 \%$. Nine patients $(2.88 \%)$ achieved euthyroidism, and early hypothyroidism occurred in 218 (69.87\%) patients. The 131 I therapy was ineffective in 85 patients $(27.24 \%)$. In 85 patients who failed the first time RAI, 84 underwent a second RAI treatment and all of them became permanently hypothyroid. Only 1 patient underwent a thyroidectomy and was euthyroid after 6 months' follow-up.

\section{Explore the risk factors affecting the occurrence of early hypothyroidism}

As shown in Table 2, there were 94 patients with nonhypothyroidism, including 4 males and 90 females; 218 patients with early hypothyroidism, including 50 males and 168 females. Gender, duration of disease, thyroid weight, 2-h RAIU, 6-h RAIU, 24-h RAIU, 6/24-h uptake ratio and dose of RAI were significantly different between non-hypothyroid group and hypothyroid group. As shown in Table 3, taking the incidence of hypothyroidism as the dependent variable, a binary 


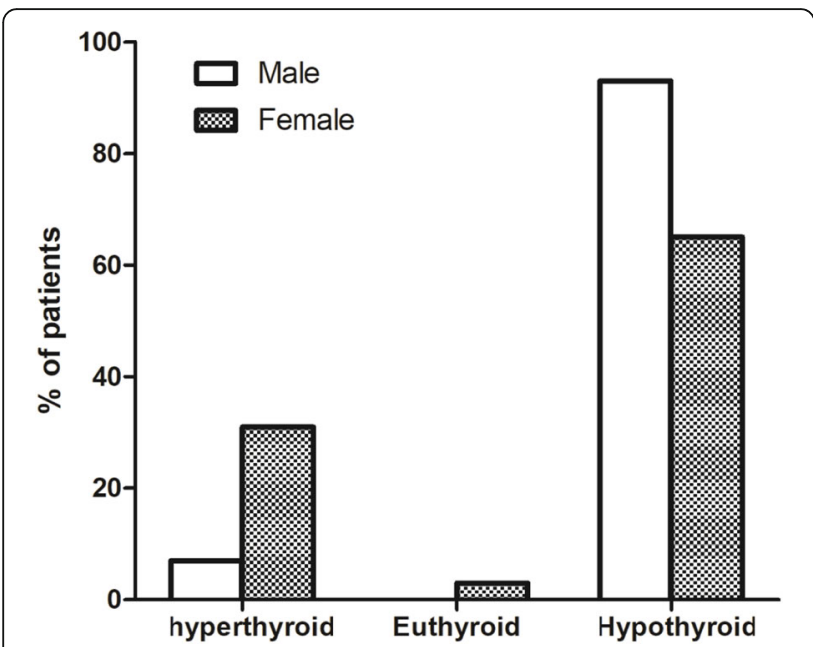

Fig. 3 The thyroid function of the patients six months after RAl treatment

logistic regression was performed, and the results showed that male gender, smaller thyroid weight and lower 6-h RAIU were associated with early hypothyroidism. At last, multi-factors combined ROC curve analysis suggested that the predictive power of male gender, smaller thyroid weight and lower 6-h RAIU for early hypothyroidism was 0.711 (Fig. 2).

\section{Discussion}

RAI therapy for the treatment of GD has been used since the 1940s [16] and now it is still one of the most important treatments for GD $[17,18]$. In most countries around the world, a fixed dose of iodine 131 is generally used for treatment. Both euthyroidism and hypothyroidism are considered a successful therapy. However, the RAI use is decreasing even in the United

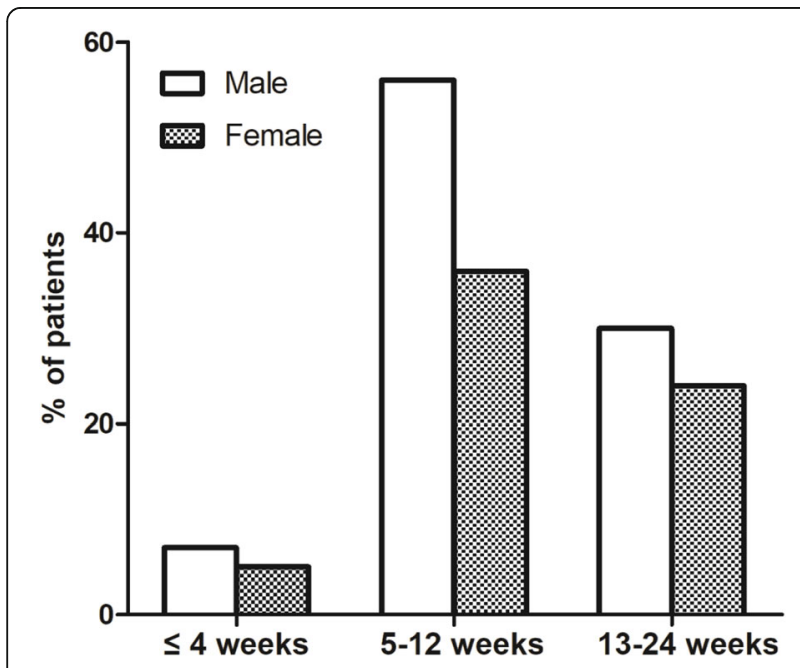

Fig. 4 The occurrence of hypothyroidism after RAl treatment within six months
States in the past decade, partly because a preference to avoid hypothyroidism and lifelong hormone replacement [19]. In this study, we use the calculated dose method to determine the dose of iodine 131, and try to find the influence factors of hypothyroidism during RAI treatment.

It has been reported that the majority of GD occurs between 30 and 60 years old, most of them were females, with a male to female ratio of about 1:3-1:10 [1, 2, 9]. Our study showed that the average age of the patients was $45.07 \pm 12.59$ years and the ratio of male to female was $1: 4.78$, which was similar to the previous reports. In the literatures, the incidence of hypothyroidism after RAI therapy ranged from 8.5 to $90 \%[20-24]$. Our results indicated that the early hypothyroidism occurred in 218 (69.87\%) patients, and only nine patients (2.88\%) achieved euthyroidism, which was consistent with a recent study conducted in Singapore [25].

Most of the previous studies suggested that there were no differences in the incidence of hypothyroidism between men and women after RAI treatment. However, some studies have suggested that female gender to be an independent predictor of hypothyroidism [26, 27]. In our study, as shown in Fig. 3 and Figs. 4, 50 of 54 male patients occured early hypothyroidism, but only 168 of the 258 female patients had early hypothyroidism. More than 50\% male patients became hypothyroid in 4-12 weeks after RAI therapy, but only $36 \%$ female patients became hypothyroid at that time. There was a significant statistical difference between men and women. The subsequent logistic regression analysis also suggested that male gender was a risk factor of early hypothyroidism even accounting for other clinical factors. This is quite different with the previous studies, but we found recently a research of Malaysia also prompt that men became to hypothyroid easier than women [28]. We hypothesized that the difference may be because the genetic susceptibility among different races.

De Jong et al. believed that larger thyroid volumes $(>50$ $\mathrm{mL})$ and increasing 5/24-h 131I turnover $(\geq 0.8)$ are independent risk factors of hypothyroidism [13]. Yang et al. showed that RAI treatment was more successful in patients with lower weight of the thyroid [29]. We found that the non-hypothyroid patients had a median thyroid weight of $60.83 \mathrm{~g}$, but the hypothyroid patients only 49.82 g. We also found the non-hypothyroid patients had higher $2 \mathrm{~h}, 6 \mathrm{~h}, 24 \mathrm{~h}$ thyroid iodine uptake rate and $6 \mathrm{~h} / 24 \mathrm{~h}$ thyroid iodine uptake rate than hypothyroid patients (Table. 2), this is consistent with previous researches.

Some studies demonstrated that FT3 level, FT4 level, TSH level and TRAb titre before RAI treatment were significantly associated with treatment failure of RAI [30, 31], but we didn't find the associations in our study. Perhaps because these factors are too weak to affect the occurrence of hypothyroid. 


\section{Conclusions}

In short, our study demonstrated that male gender, $6 \mathrm{~h}$ thyroid iodine uptake rate and thyroid weight are associated with early hypothyroid after RAI therapy. Adjust the treatment dose in these patients may decrease the occurrence of early hypothyroidism and improve the outcome of RAI therapy.

\section{Abbreviations}

ATD: Anti-thyroid drugs; FT3: Free triiodothyronine; FT4: Free thyroxine; GD: Graves' disease; RAl: Radioactive iodine; RAIU: Radioactive iodine uptake; TPOAb: Thyroperoxidase antibody; TRAb: Thyrotropin receptor antibody; TSH: Thyrotropin

\section{Acknowledgments}

The authors thank Li-ming Zhao and Zhong-guang Xue provided assistance for statistical analysis and manuscript preparation.

\section{Authors' contributions}

Research idea and study design: $\mathrm{RH}, \mathrm{DL}$ and $\mathrm{BL}$; data acquisition and analysis: $\mathrm{RH}$ and $\mathrm{BL}$; statistical analysis: $\mathrm{DL}$; wrote the paper: $\mathrm{RH}, \mathrm{DL}$ and $\mathrm{BL}$. All authors have read and approved the manuscript

\section{Funding}

This work was funded by the National Natural Science Foundation of China (Grant No. 81173250), the Project of Natural Foundation of Shandong Province, China (Project No.ZR2014HP026 and ZR2017MH039), the Shandong Province traditional Chinese medicine science and technology development plan project (Project No.2017-466) and the Shandong Province medical and health science and technology development plan project (Project No. 2017WS498)

\section{Availability of data and materials}

The data used to support the findings of this study are available from the corresponding author upon request.

\section{Ethics approval and consent to participate}

The study was approved by the ethics committee of Linyi People's Hospital Affiliated to Shandong University and was performed in accordance with the guidelines and regulations. Informed written consent was obtained from the all patients.

\section{Consent for publication}

Not applicable.

\section{Competing interests}

The authors declare that there is no competing interests regarding the publication of this paper.

\section{Author details \\ 'Department of Traditional Chinese Medicine, Qilu Hospital, Cheeloo College of Medicine, Shandong University, Jinan 250012, Shandong, China. 2Department of Endocrinology, Hospital of Traditional Chinese Medicine of Linyi City, Linyi 276002, Shandong, China. ${ }^{3}$ Department of Nuclear Medicine, Linyi People's Hospital, Cheeloo College of Medicine, Shandong University, Linyi 276000, Shandong, China.}

Received: 3 March 2020 Accepted: 21 May 2020

Published online: 29 May 2020

\section{References}

1. Smith TJ, Longo DL, Hegedüs L. Graves' disease. N Engl J Med. 2016;375(16): 1552-65.

2. Hussain YS, Hookham JC, Allahabadia A, Balasubramanian SP. Epidemiology, management and outcomes of graves' disease—real life data. Endocrine. 2017;56(3):568-78.

3. Azizi F, Malboosbaf R. Long-term Antithyroid drug treatment: a systematic review and meta-analysis. Thyroid. 2017;27(10):1223-31.
4. Wiersinga WM. Graves' disease: can it be cured? Endocrinol Metab. 2019; 34(1):29.

5. Sjölin G, Holmberg M, Törring O, Byström K, Khamisi S, de Laval D, Abraham-Nordling M, Calissendorff J, Lantz M, Hallengren B, et al. The longterm outcome of treatment for Graves' hyperthyroidism. Thyroid. 2019; 29(11):1545-57.

6. Franklyn JA, Boelaert K. Thyrotoxicosis. Lancet. 2012;379(9821):1155-66.

7. Sundaresh V, Brito JP, Wang Z, Prokop LJ, Stan MN, Murad MH, Bahn RS. Comparative effectiveness of therapies for Graves' hyperthyroidism: a systematic review and network meta-analysis. J Clin Endocrinol Metab. 2013; 98(9):3671-7.

8. Masiello E, Veronesi G, Gallo D, Premoli P, Bianconi E, Rosetti S, Cusini C, Sabatino J, Ippolito S, Piantanida E, et al. Antithyroid drug treatment for graves' disease: baseline predictive models of relapse after treatment for a patient-tailored management. J Endocrinol Investig. 2018:41(12):1425-32.

9. Sundaresh V, Brito JP, Thapa P, Bahn RS, Stan MN. Comparative effectiveness of treatment choices for Graves' hyperthyroidism: a historical cohort study. Thyroid. 2017;27(4):497-505.

10. Aung ET, Zammitt NN, Dover AR, Strachan MWJ, Seckl JR, Gibb FW Predicting outcomes and complications following radioiodine therapy in graves' thyrotoxicosis. Clin Endocrinol. 2019;90(1):192-9.

11. Li J, Zhang L, Zhang Z, Liu J, Zhang H, Lin X, Jiang N. Factors suggesting relapse of Grave's disease after first radioiodine therapy. Analysis of 607 cases. Hell J Nucl Med. 2019;22(1):64-9.

12. Xing $Y Z$, Zhang $K$, Jin G. Predictive factors for the outcomes of Graves' disease patients with radioactive iodine (131l) treatment. Biosci Rep. 2019;40(1).

13. de Jong JA, Verkooijen HM, Valk GD, Zelissen PM, de Keizer B. High failure rates after (131) I therapy in graves hyperthyroidism patients with large thyroid volumes, high iodine uptake, and high iodine turnover. Clin Nucl Med. 2013:38(6):401-6

14. Zheng W, Jian T, Guizhi Z, Zhaowei M, Renfei W. Analysis of 131i therapy and correlation factors of graves'disease patients. Nucl Med Commun. 2012; 33(1):97-101.

15. Leslie WD, Ward L, Salamon EA, Ludwig S, Rowe RC, Cowden EA. A randomized comparison of radioiodine doses in Graves' hyperthyroidism. J Clin Endocrinol Metab. 2003:88(3):978-83.

16. Ross DS, Burch HB, Cooper DS, Greenlee MC, Laurberg P, Maia AL, Rivkees SA, Samuels M, Sosa JA, Stan MN, et al. 2016 American Thyroid Association guidelines for diagnosis and Management of Hyperthyroidism and Other Causes of thyrotoxicosis. Thyroid. 2016;26(10):1343-421.

17. Burch HB, Burman KD, Cooper DS. A 2011 survey of clinical practice patterns in the management of Graves' disease. J Clin Endocrinol Metab. 2012;97(12):4549-58.

18. Bartalena L, Burch HB, Burman KD, Kahaly GJ. A 2013 European survey of clinical practice patterns in the management of Graves' disease. Clin Endocrinol. 2016:84(1):115-20.

19. Seib CD, Chen J, lagaru A. Shifting trends and informed decision making in the Management of Graves' disease. Thyroid. 2020.

20. Chiovato L, Fiore E, Vitti P, Rocchi R, Rago T, Dokic D, Latrofa F, Mammoli C,

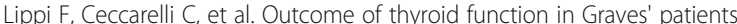
treated with radioiodine: role of thyroid-stimulating and thyrotropinblocking antibodies and of radioiodine-induced thyroid damage. J Clin Endocrinol Metab. 1998;83(1):40-6.

21. Walter MA, Christ-Crain M, Eckard B, Schindler C, Nitzsche EU, Muller-Brand J, Muller B. Radioiodine therapy in hyperthyroidism: inverse correlation of pretherapeutic iodine uptake level and post-therapeutic outcome. Eur J Clin Investig. 2004;34(5):365-70.

22. Nakajo M, Tsuchimochi S, Tanabe H, Nakabeppu $Y$, Jinguji M. Three basic patterns of changes in serum thyroid hormone levels in Graves' disease during the one-year period after radioiodine therapy. Ann Nucl Med. 2005; 19(4):297-308.

23. Enyi Ejeh MJ, Omotayo Ogunjobi K, Enyi Ejeh J, Solomon Adedapo K. J FE: effectiveness of fixed dose radioactive iodine (RAl) for the treatment of hyperthyroidism: experience of a teaching hospital in south West Nigeria. Mol Imaging Radionucl Ther. 2013:22(2):36-41.

24. Beslic N, Licina S, Sadija A, Milardovic R. Incidence of Hypothyreoidism after radioactive iodine-1131 treatment in Dependance of Hyperthyreoidism etiology and therapy dose. Med Arch. 2017;71(4):270-3.

25. Tay WL, Chng CL, Tien CS, Loke KS, Lam WW, Fook-Chong SM, Tong AK High thyroid stimulating receptor antibody titre and large goitre size at first-time radioactive iodine treatment are associated with treatment failure in Graves' disease. Ann Acad Med Singap. 2019;48(6):181-7. 
26. Alevizaki CC, Alevizaki-Harhalaki MC, Ikkos DG. Radioiodine-131 treatment of thyrotoxicosis: dose required for and some factors affecting the early induction of hypothyroidism. Eur J Nucl Med. 1985;10(9-10):450-4.

27. Boelaert K, Syed AA, Manji N, Sheppard MC, Holder RL, Gough SC, Franklyn JA. Prediction of cure and risk of hypothyroidism in patients receiving 1311 for hyperthyroidism. Clin Endocrinol. 2009;70(1):129-38.

28. Wan Mohamed WMI, Sayuti SC, Draman N. Hypothyroidism and its associated factors after radioactive iodine therapy among patients with hyperthyroidism in the northeast coast state of Malaysia. J Taibah Univ Med Sci. 2018;13(5):432-7.

29. Yang D, Xue J, Ma W, Liu F, Fan Y, Rong J, Yang A, Yu Y. Prognostic factor analysis in 325 patients with Graves' disease treated with radioiodine therapy. Nucl Med Commun. 2018;39(1):16-21.

30. Sapienza MT, Coura-Filho GB, Willegaignon J, Watanabe T, Duarte PS, Buchpiguel CA. Clinical and Dosimetric variables related to outcome after treatment of Graves' disease with 550 and $1110 \mathrm{MBq}$ of 1311: results of a prospective randomized trial. Clin Nucl Med. 2015;40(9):715-9.

31. Sfiligoj D, Gaberscek S, Mekjavic PJ, Pirnat E, Zaletel K. Factors influencing the success of radioiodine therapy in patients with Graves' disease. Nucl Med Commun. 2015;36(6):560-5.

\section{Publisher's Note}

Springer Nature remains neutral with regard to jurisdictional claims in published maps and institutional affiliations.

Ready to submit your research? Choose BMC and benefit from:

- fast, convenient online submission

- thorough peer review by experienced researchers in your field

- rapid publication on acceptance

- support for research data, including large and complex data types

- gold Open Access which fosters wider collaboration and increased citations

- maximum visibility for your research: over $100 \mathrm{M}$ website views per year

At BMC, research is always in progress.

Learn more biomedcentral.com/submissions 